\title{
Vino, lenguaje y publicidad
}

\author{
Isidoro Ramírez Almansa \\ Universidad de Córdoba \\ II2raali@uco.es \\ https://dx.doi.org.10.12795/futhark.2016.il I.09
}

Fecha de recepción: 17.10.2016

Fecha de aceptación: 15.12.2016

Resumen: El presente trabajo aborda las principales características del lenguaje publicitario referido a la elaboración, la comercialización y el consumo del vino, entendido como elemento dinamizador y catalizador de las tendencias de consumo. Para ello, se parte de la selección de una serie de bodegas españolas, en las que tomamos como referencia, en primer lugar, el tiempo que éstas llevan dentro del sector; en segundo lugar, la producción de vinos tintos, blancos y rosados; y, finalmente, el volumen de producción, esto es, bajo, medio o alto. A partir de ejemplos concretos analizaremos los efectos que éstos pueden producir en el consumidor final, y obtendremos las respectivas conclusiones.

Palabras clave: vitivinicultura, lenguaje especializado, publicidad, terminología, eslogan publicitario, vino.

\section{Wine, language and publicity}

\begin{abstract}
This paper aims to outline the main characteristics of the publicity language referring to the winemaking, its commercialisation and consumption. This must be understood as an element that vitalises and activates the consumption tendencies. For this purpose, we start from a selection of Spanish wineries where we study, firstly, the period of its business activity; secondly, the production of white, red and rosé wines; and, finally, the volume of production (low, medium, high). According to exposed examples, we will analyse the effects on the final customer as well as we will establish the corresponding conclusions.
\end{abstract}

Key words: Wine-growing, specialized language, publicity, terminology, slogan, wine. 
Sumario: Introducción. I. Metodología. 2. El lenguaje publicitario del vino: algunos ejemplos. 2.I. La tradición como sinónimo de calidad. 2.2. Equilibrio entre tradición e innovación. 2.3. El valor de lo ecológico 2.4. El vino como experiencia y signo de estatus social. 2.5. El papel protagonista de la mujer. 2.6. El protagonismo de la juventud. 2.7. El apego a la tierra. Conclusiones.

\section{Introducción}

Existen numerosos estudios acerca del sector vitivinícola y de la vitivinicultura, llevados a cabo desde distintos puntos de vista. Así, desde el punto de vista científico, tenemos estudios que abordan la enología y disciplinas afines tales como la botánica, la geología o la meteorología (Blouin 2004; Hidalgo 2002; Hidalgo 20I I; Reynier 2002); otros, analizan el mundo del vino desde presupuestos históricos y culturales (Balbuena 20I5a; lbáñez 2002); en ocasiones, los trabajos se centran en parámetros relativos al marketing y a cuestiones económicas (Albisur 2003; Gómez 2003; Muñoz 2007). Desde el punto de vista de la lengua y la comunicación, cabe destacar estudios de tipo lingüístico y contrastivo, haciendo referencia a la terminología propia del sector (Bajo 200l y 2007), y, finalmente, también encontramos otros dirigidos a la traducción de textos (Balbuena y Álvarez 2015; Barahona 2010; Ibáñez 2003 y 2006).

En las páginas siguientes analizaremos el papel que juega el lenguaje para la promoción y el consumo del vino, y cómo puede igualmente contribuir a la evolución del sector vitivinícola.

\section{Metodología}

Para abordar este trabajo, hemos tomado como ejemplo la publicidad del vino de distintas bodegas y grupos bodegueros extendidos a lo largo de la península. Cabe señalar, no obstante, que las bodegas elegidas se dedican a la elaboración de los tres principales grupos de vino: tintos, blancos y rosados. Del mismo modo, se ha procurado tomar como representativas bodegas con una larga tradición en la elaboración de los caldos, así como otras de reciente formación. Finalmente, se ha tenido en cuenta el volumen de producción, y así encontramos bodegas con volumen medio, bajo y alto en lo que a productividad se refiere.

\section{El lenguaje publicitario del vino: algunos ejemplos}

\section{I. La tradición como sinónimo de calidad}

Uno de los recursos fundamentales en la publicidad y la información vinícola es la promoción de un determinado vino como fruto de una larga tradición familiar 
y la solera y la antigüedad de las instalaciones en las que éste es elaborado: barricas centenarias, lagares, y construcciones de siglos pasados, fruto de un legado familiar, son los elementos que permiten a una determinada bodega diferenciarse de otras de reciente aparición, $y$, por tanto, considerada como "nuevo productor" dentro del sector. Veamos algunos ejemplos:

(I) "Una historia ligada al saber de nuestros antepasados, Verum excelencia del vino manchego" (Bodegas Verum')

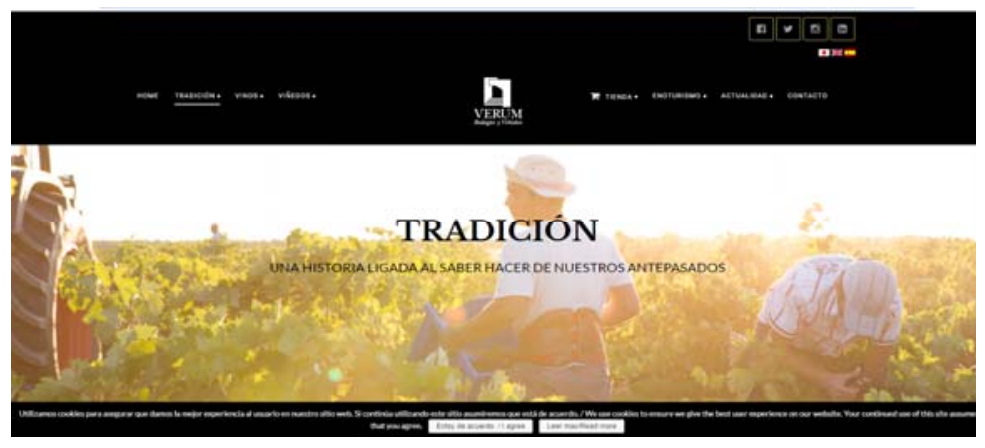

Imagen I: Verum Bodegas y viñedos.

(2) "Más de cuatro décadas con una única obsesión: la calidad" (Bodegas Marqués de Cáceres $^{2}$ )

' Fuente: https://www.bodegasverum.com/es/tradicion/. [Fecha de consulta: 03.09.2016].

${ }^{2}$ Fuente: http://enogourmet.blogspot.com/2016/07/gaudium-tinto-reserva-2009-bodegas.html. [Fecha de consulta: 03.09.2016]

Futhark II (2016) 


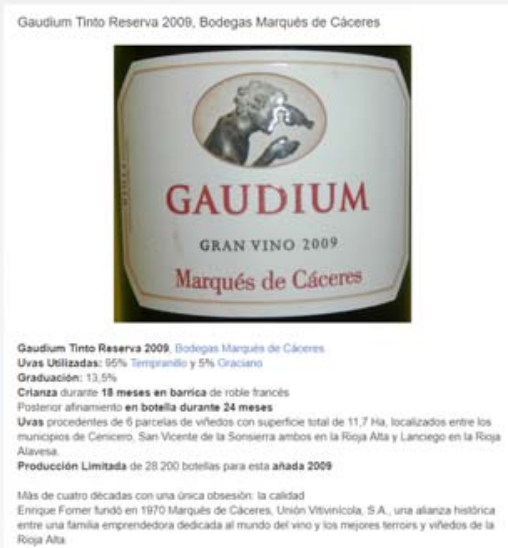

Imagen 2: Gaudium Tinto Reserva 2009. Bodegas Marqués de Cáceres.

(3) “Una vuelta al pasado, a nuestra historia, a nuestras tradiciones" (Grupo Yllera ${ }^{3}$ )

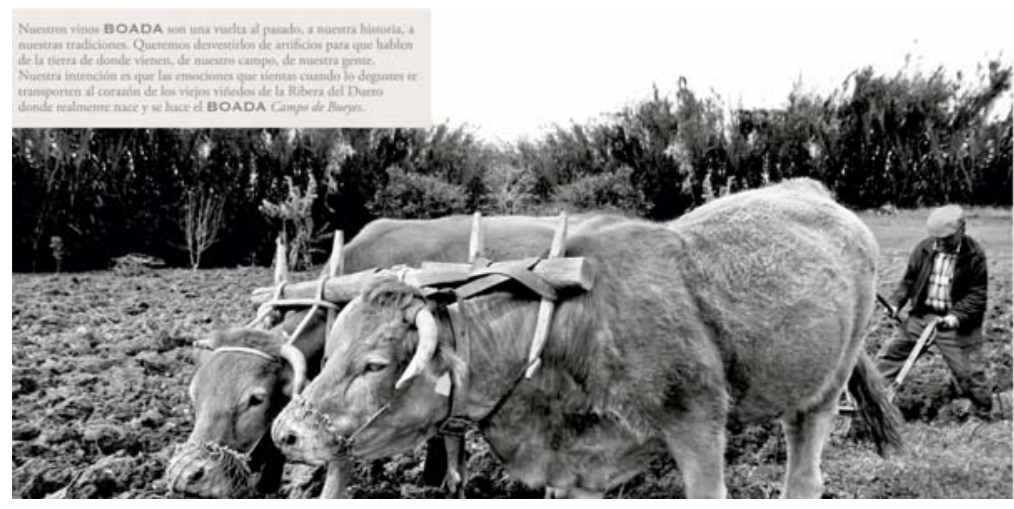

Imagen 3: Catálogo vinos BOADA. Grupo Yllera.

${ }^{3}$ Fuente: https://www.grupoyllera.com/imagenes/productos/71_Catalogo_Boada_Espanol.pdf. [Fecha de consulta: 03.09.2016]. 
(4) "La filosofía de Finca Moncloa se basa en recuperar la tradición casi olvidada de elaborar vinos tintos" (Bodegas Gonzalez Byass ${ }^{4}$ )
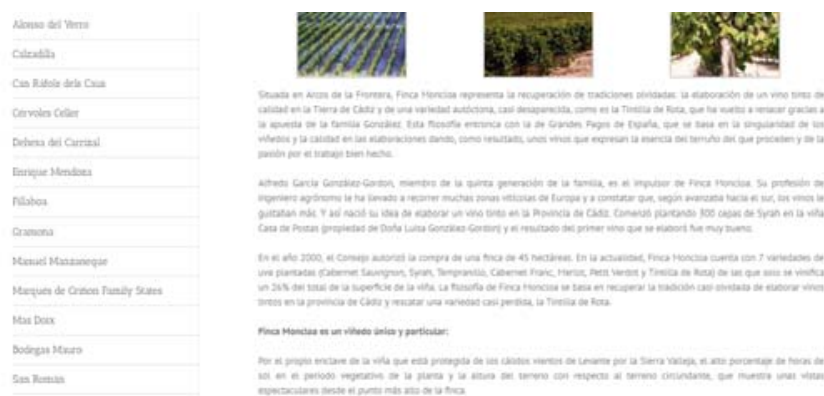

Imagen 4: Finca Moncloa. Bodegas Gonzalez Byass.

(5) "Diferentes generaciones de viticultores que aman su tierra" (Premium Fincas)

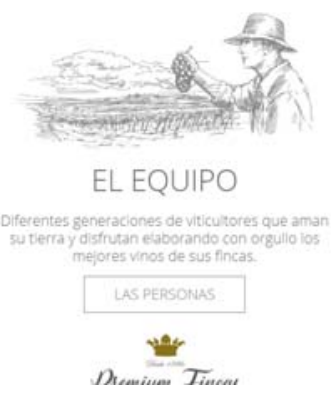

Imagen 5: Premium Fincas.

\subsection{Equilibrio entre tradición e innovación.}

Uno de los principales valores que se pone de manifiesto para la comercialización de un producto, sea cual sea, es la experiencia en su producción o fabricación, unida a un amplio conocimiento del know how, así como de los últimos avances en $I+D+i$ del sector. Este conocimiento exhaustivo, unido al transcurrir del tiempo, y a la conservación de tradiciones y elaboraciones artesanales, es el

${ }^{4}$ Fuente: https://grandespagos.com/bodegas/finca-moncloal. [Fecha de consulta: 03.09.2016]. 
empleado por numerosas bodegas como recurso fundamental para la venta de sus vinos. Algunos ejemplos son los siguientes:

(6) "El equilibrio entre tradición y modernidad es el único camino para seguir como siempre". "Ser una bodega clásica no implica hacer un vino antiguo" (Bodegas Riojanas ${ }^{5}$ )

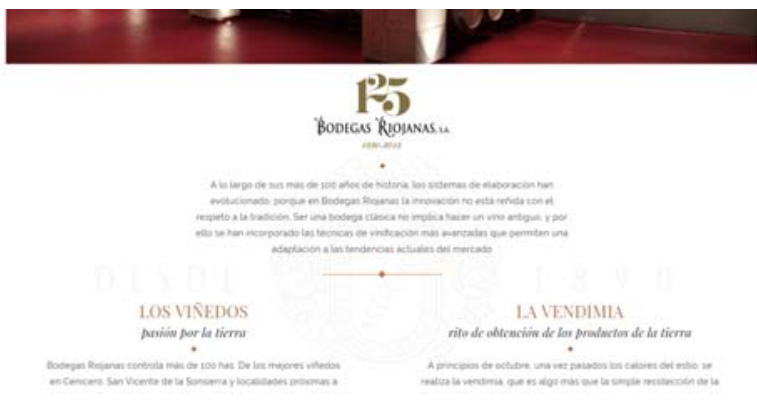

Imagen 6: Bodegas Riojanas.

(7) "Inquieta y renovadora, no ajena a la evolución, compagina el respeto por la tradición y la innovación” (Bodegas Franco-Españolas ${ }^{6}$ )

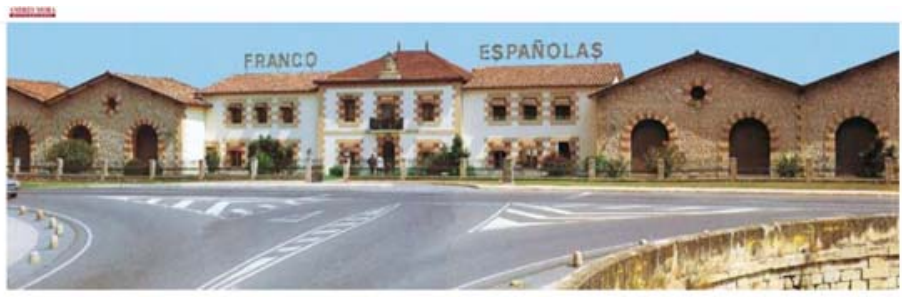

BODEGAS FRANCO ESPANDOLAS ENEL STGLOOM

HISTORIA DE BDDEGaS FRANCO ESPAÑOLAS

Imagen 7: Bodegas Franco-Españolas.

${ }^{5}$ Fuente: http://bodegasriojanas.com/es/bodega/bodegas-riojanas. [Fecha de consulta: 05. 09.2016].

6 Fuente: http://www.andresmoradistribuciones.com/productos/bodegas-franco-espanolas/. [Fecha de consulta: 05.09.2016]. 
(8) “Desde la autenticidad, sumando tradición y modernidad". "Una bodega moderna con el mejor legado de los métodos tradicionales". "Vinos con tradición y presente" (Bodegas Luberri)

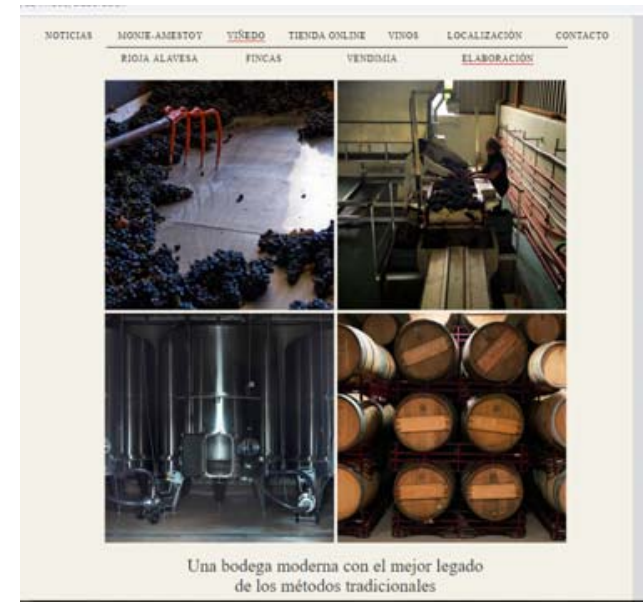

Imagen 8: Bodegas Luberri.

(9) “Modernidad y tradición se ensamblan” (Finca Las Caraballas)

\section{icaraballas}

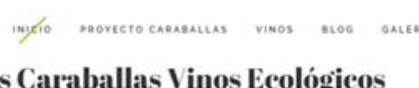

Finca Las Caraballas Vinos Ecológieos

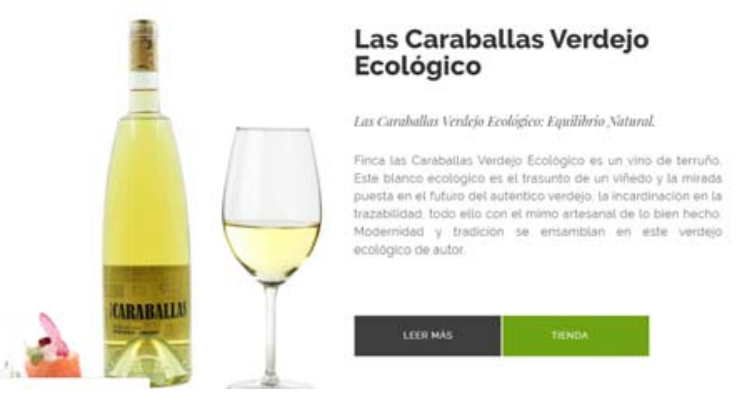

Imagen 9: Bodegas Caraballas. 


\subsection{El valor de lo ecológico}

Cuando un consumidor opta por adquirir un vino ecológico, por lo general de un precio más elevado, probablemente se deba, fundamentalmente, a que piensa que está bebiendo un vino más saludable que el resto de vinos. Junto a esta razón, cabe señalar que también existe un mercado de consumidores altamente concienciados con el medioambiente -véase, por ejemplo, mercados como Alemania o Suecia-, y en definitiva, la percepción de cuidar la propia alimentación y el planeta en el que vivimos. Esto supone, para las bodegas, un nicho de mercado que se caracteriza por la exquisitez y también por poseer un alto poder adquisitivo. Por ello, la inmensa mayoría de productores se esfuerzan por publicitar un vino natural, en concordancia con el medioambiente, y tipificado como "ecológico" o "biológico". Veamos algunos ejemplos significativos:

(10) “La viticultura ecológica es mucho más que una forma de agricultura, es una filosofía” (Bodegas Robles')

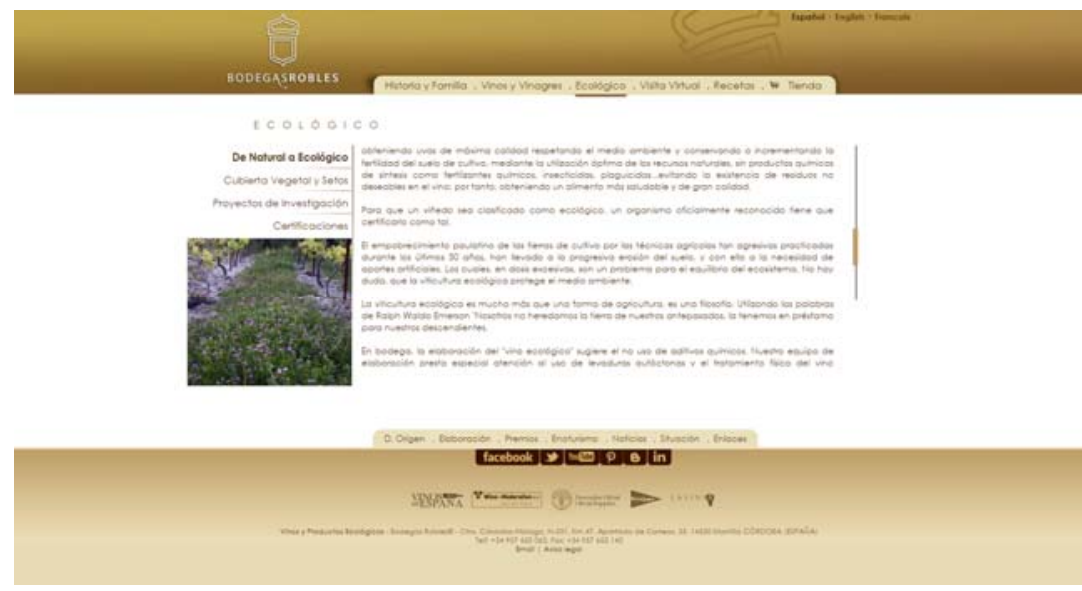

Imagen 10: Bodegas Robles.

${ }^{7}$ Fuente: https://www.bodegasrobles.com/espanol/ecologico.php. [Fecha de consulta: 08.09.2016]. 
(II) "La calidad del producto y el respeto por el medio ambiente es nuestro mayor objetivo" (Bodegas Lezaun ${ }^{8}$ )

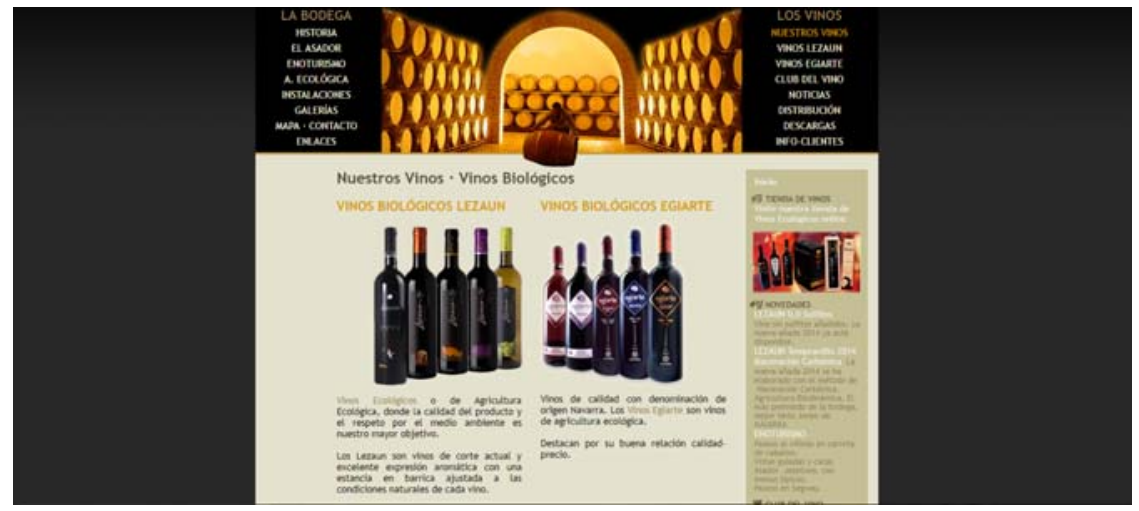

Imagen II: Bodegas Lezaun.

(I2) “(...) integrar el uso de una agricultura respetuosa en el medio natural de nuestro ecosistema” (Finca Santa Rosalía')

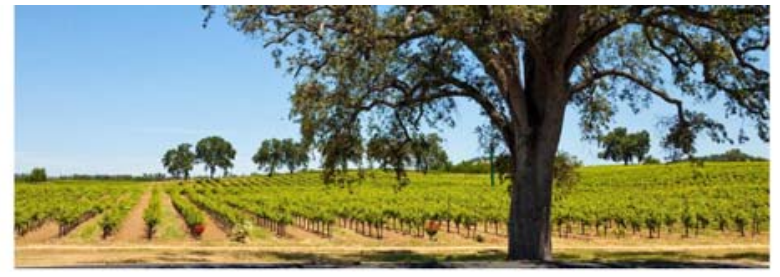

Tor que muestros vinas sen ecolidigcont

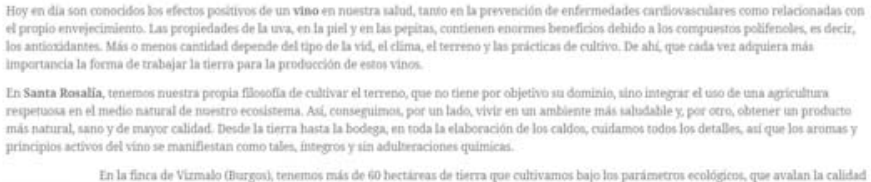

Imagen 12: Finca Santa Rosalía.

8 Fuente: http://www.lezaun.com/p/es/Vino-Biologico/Vinos-Biologicos.php. [Fecha de consulta: 08.09.2016].

${ }^{9}$ Fuente: https://www.fincasantarosalia.com/por-que-nuestros-vinos-son-ecologicos/. [Fecha de consulta: 08.09.2016].

Futhark II (2016) 


\subsection{El vino como experiencia y signo de estatus social}

Otra de las cualidades del consumo de vino es su carácter hedonista y el vínculo directo que tiene con la esfera social del individuo, de forma que también en la publicidad de las bodegas es posible encontrar alusiones a la experiencia sensorial y placentera que supone beber una copa de vino, y el carácter sofisticado que confiere a quien sabe apreciar las cualidades de un buen vino. Así lo muestran los siguientes ejemplos:

(13) Marqués de Cáceres ofrece un vino para disfrutar y compartir" (Marqués de Cáceres ${ }^{10}$ )

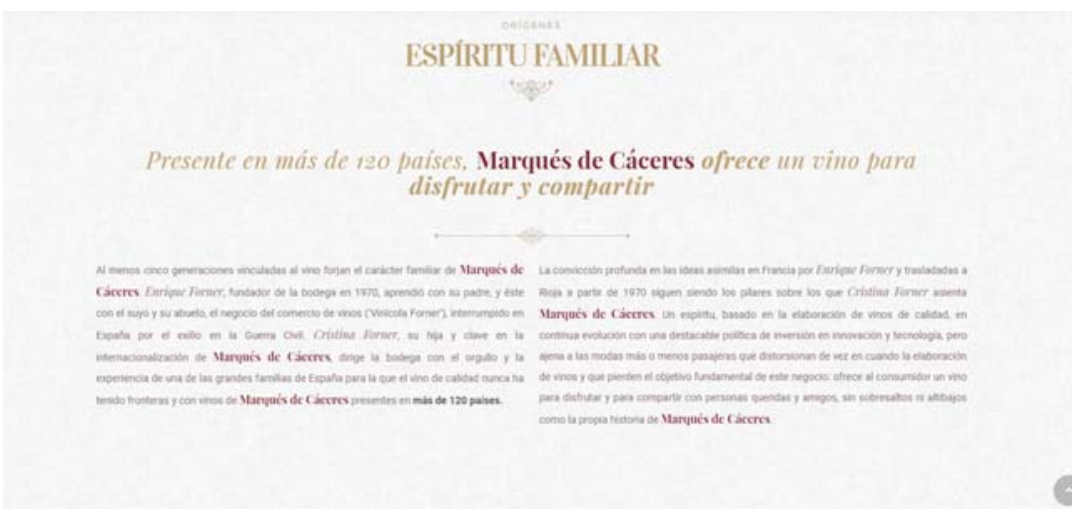

Imagen I3: Bodegas Marqués de Cáceres.

10 Fuente: https://www.marquesdecaceres.com/historia-marques-de-caceres/. [Fecha de consulta: 08.09.2016]. 
(14) “Amor, pasión y respeto por el vino” (Casa Rojo")

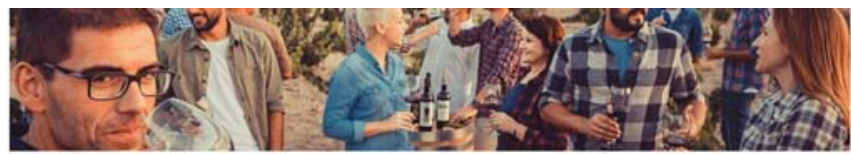

CASA ROJO

\section{CASA GRROJO}
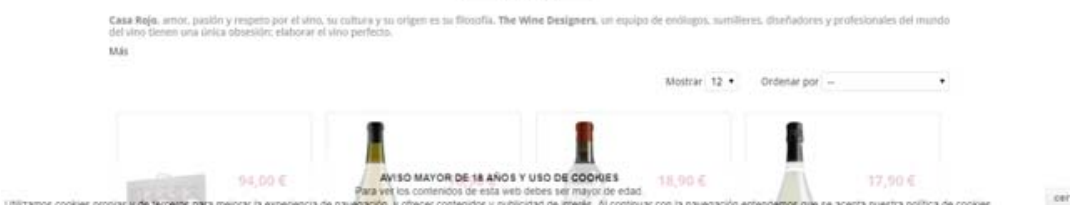

Imagen I4: Casa Rojo.

(15) "Vive la experiencia del vino". "El vino es una experiencia en si" (Bodegas Verum'2)

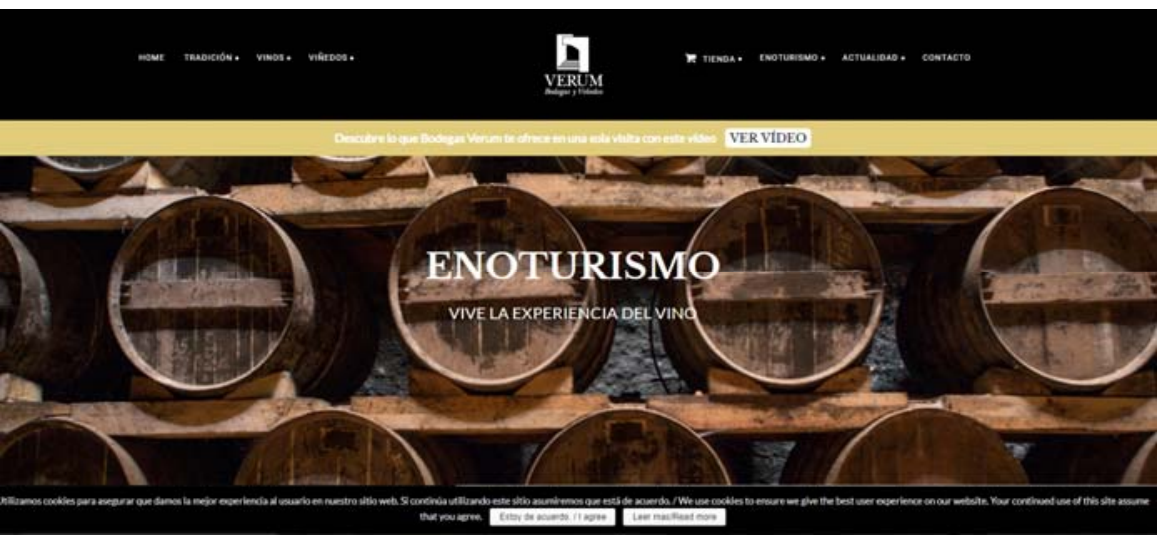

Imagen I5: Bodegas Verum.

"Fuente: https://www.mundovinum.com/260 casa-rojo. [Fecha de consulta: 08.09.2018].

${ }^{12}$ Fuente: https://www.bodegasverum.com/es/enoturismo/visitanos/. [Fecha de consulta: 08.09.2018]

Futhark II (2016)

$|3|-\mid 48$ 


\subsection{El papel protagonista de la mujer}

La mujer ha sido otro eslabón tradicionalmente olvidado, y podríamos decir incluso excluido, dentro del colectivo de consumidores de vino. En el pasado, la cultura popular identificaba el vino como una bebida exclusiva para el hombre. La evolución cultural y la llegada del género femenino a prácticamente todos los sectores de la sociedad y de la actividad social y empresarial, hacen que el mercado femenino sea una de las principales esperanzas del sector vitivinícola para impulsar el consumo de vino en nuestro país. Junto a la fraseología y los slogans cabe señalar que la mujer ocupa un lugar de honor ya desde el mismo nombre que se le confiere al producto, $y$ así hay bodegas que deciden poner un nombre femenino a sus vinos, como por ejemplo: Rita (Bodega Habla), Carmen (Bodega Cantador), Eva (Bodegas Barbadillo), María (Viñedos Alonso del Yerro).

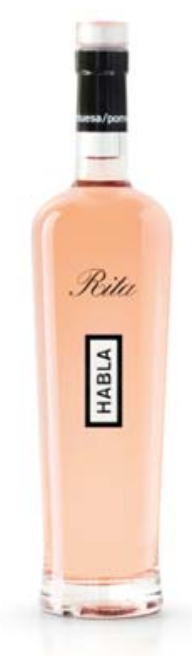

Imagen 16: Vino Rita (Bodega Habla).

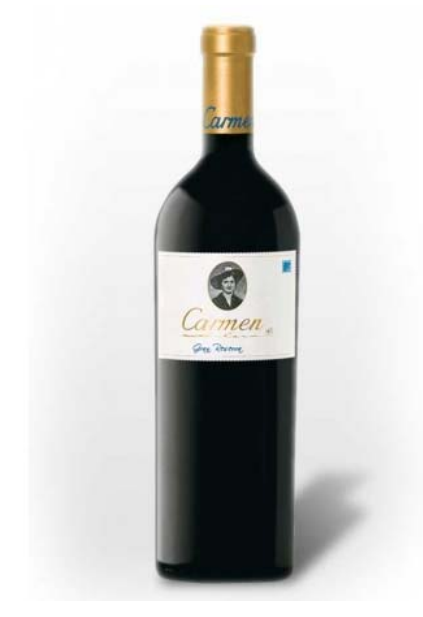

Imagen 17: Vino Carmen (Bodega Cantador).

\subsection{El protagonismo de la juventud}

Se considera que el consumidor joven de vino es aquel comprendido entre los 18 y 35 años de edad, teniendo en cuenta, fundamentalmente, el acceso al mercado laboral de las personas y el poder adquisitivo que éstas tienen desde que 
cumplen la mayoría de edad hasta llegar a una edad madura. En la actualidad, las bodegas tienden a captar este tipo de clientes, intentando, mediante el lenguaje, desechar la imagen de que consumir vino es para personas mayores, o que solo puede producirse un buen maridaje con alimentos también de elevado coste, como los ibéricos o los ahumados. Se emplean expresiones ligadas a la vida de la ciudad, los alimentos de comida rápida, y otros elementos culturales próximos a la población joven. Los siguientes ejemplos son buena muestra de ello:

(16) "Nuestros enólogos utilizan los viñedos como su lienzo, y la uva tempranillo como el ingrediente de su obra, mientras los artistas urbanos utilizan la ciudad como lienzo" (Bodegas Campo Viejo ${ }^{13}$ )

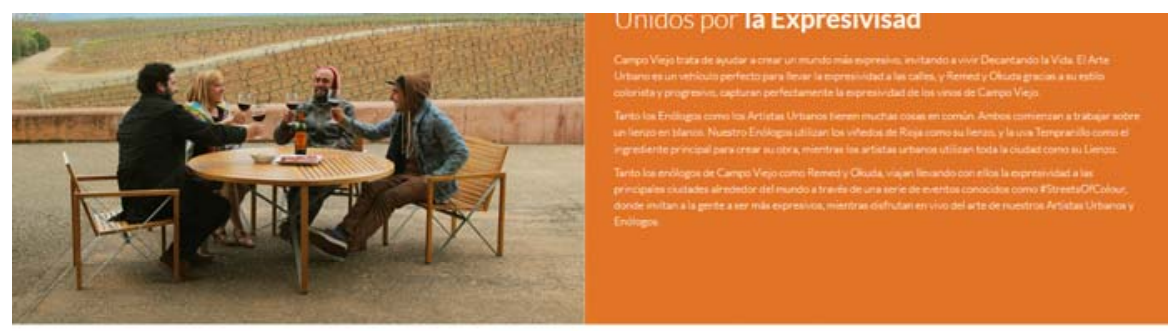

Los Eventos

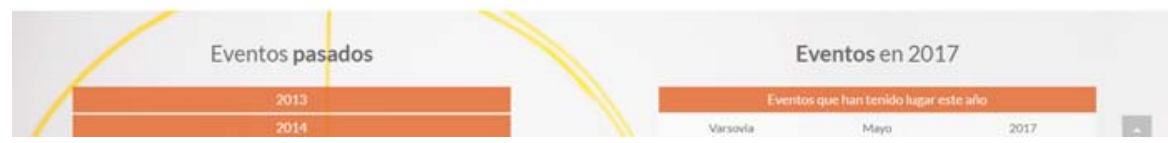

Imagen 18: Bodegas Campo Viejo

\footnotetext{
${ }^{13}$ Fuente: https://www.campoviejo.com/es/decanta-la-vida. [Fecha de consulta: 08.09.2016]
} 
(17) "El vino perfecto para tapas, comida thai, pizzas y pasta" (Pago Los Balancines $^{14}$, en Crash Wines)

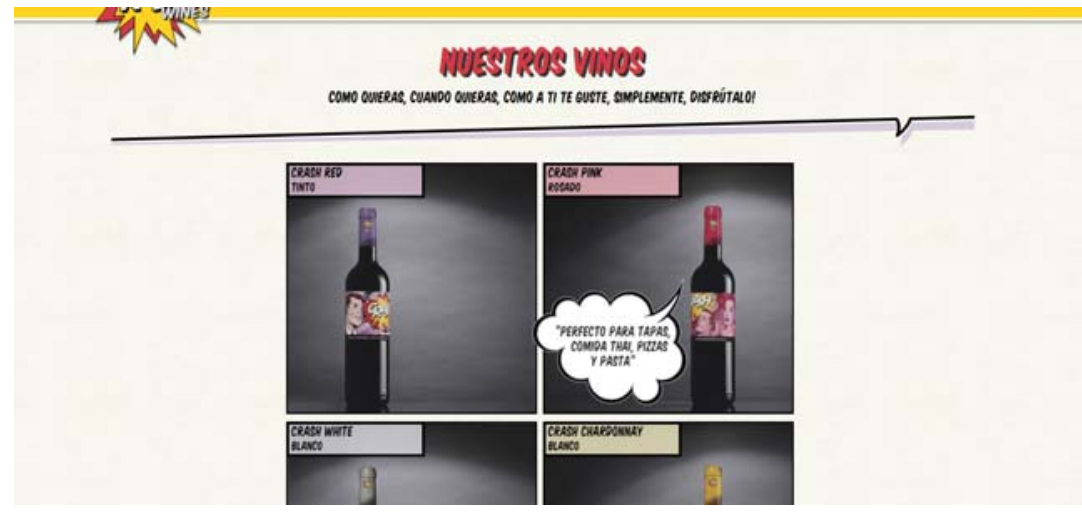

Imagen 19: Crash Wines

\subsection{El apego a la tierra}

La unión del vino con la tierra es uno de los mensajes más utilizados en la comercialización del vino. Por ello, es muy frecuente que las bodegas incidan en su publicidad que la uva de sus vinos procede de viñedos propios, para dejar claro el arraigo a la zona de cultivo en la cual se encuentran. Algunos ejemplos son los siguientes:

${ }^{14}$ Fuente: http://crashwines.com/. [Fecha de consulta: 08.09.2016]. 
(18) “En Casa Rojo entendemos el vino como la expresión de una familia, de una tierra, de un clima, de un origen en definitiva” (Casa Rojo' ${ }^{15}$ )

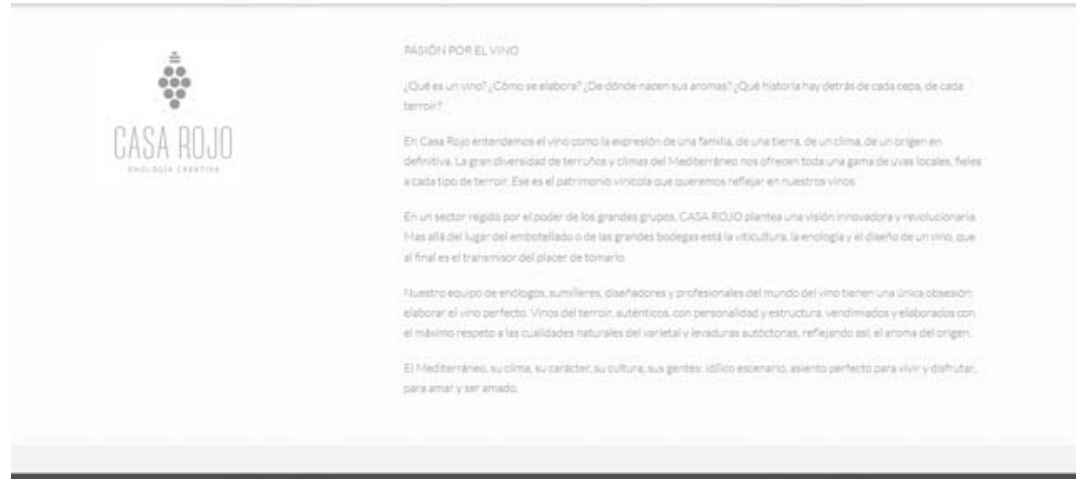

Imagen 20: Casa Rojo

(19) “Premium Fincas cuida las tierras y las viñas” (Premium Fincas ${ }^{16}$ )

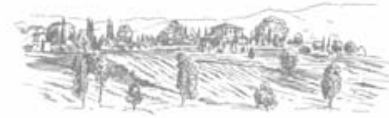

NUESTRO GRUPO

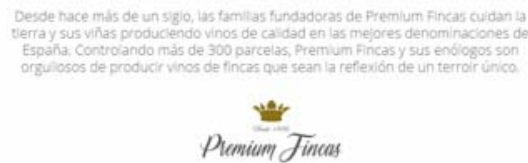

Imagen 21: Premium Fincas

${ }^{15}$ Fuente: http://www.islacatavinos.com/cata-casa-rojol. [Fecha de consulta: 08.09.2016].

${ }^{16}$ Fuente: http://premiumfincas.com/nuestro-grupol. [Fecha de consulta: 08.09.2016]. 
(20) “Un fiel reflejo de la tierra y el entorno” (Finca Las Caraballas ${ }^{17}$ )

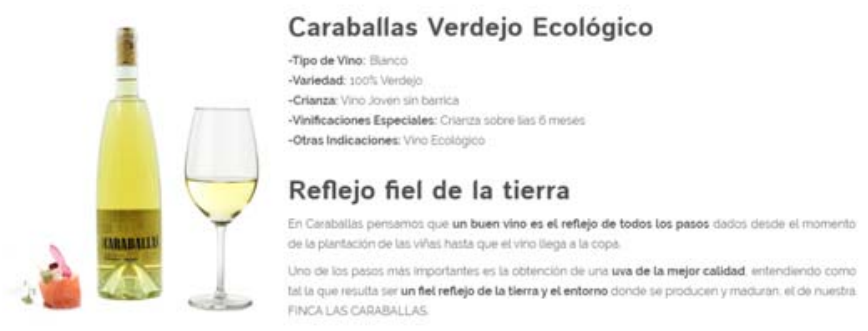

Imagen 22: Caraballas. Verdejo ecológico

\section{Conclusiones}

A tenor de lo que hemos visto en los ejemplos aquí presentados, podemos establecer las siguientes conclusiones:

I. Existe una clara relación entre el lenguaje publicitario y la realidad del sector, de forma que mediante el lenguaje podemos persuadir al receptor para que consuma un determinado vino o variedad varietal.

2. En los casos en los que se vincula la producción vinícola al legado familiar, la tradición y la elaboración artesanal, el discurso y la expresión escrita suele ir acompañado de una imagen que evidencia, o intensifica, aquello que expresan las palabras. Esta multimodalidad de imagen, color y texto, queda patente en los ejemplos (I), (3) y (5).

3. El vino ecológico, y el respeto al medio ambiente, son entendidos como un valor añadido al producto, $y$ se vende al consumidor por un lado calidad, y por el otro, salud y bienestar, consumo saludable y prolongación en el tiempo. Así se pone de manifiesto en los ejemplos (I0), (II) y (I2).

4. El vínculo del vino con la tierra, su región geográfica, la denominación de origen protegida o la pertenencia a Consejos Reguladores le aportan un "apellido geográfico" que es la garantía de calidad del vino. El valor

17 Fuente: https://lascaraballas.es/vinos-ecologicos-en-valladolid/caraballas-verdejo-ecologicol. [Fecha de consulta: 08.09.2016]. 
del origen en la naturaleza supone un plus para el producto. Así lo indican los ejemplos (18), (19) y (20).

5. Frente a tal vez otras bebidas, como los combinados con bebidas destiladas, el consumo de vino se asocia a una vida social refinada, elitista y elegante, y para ello, el lenguaje juega un papel esencial, dado que es el encargado de desechar la idea de bebida exclusiva del género masculino y de colectivos con adicción al alcohol, como muestran los ejemplos (13), (14) y (15).

6. En definitiva, no cabe duda de que la publicidad y el uso del lenguaje, inciden directamente en los cambios que pueda sufrir el sector de la vitivinicultura, hasta el punto de que el empleo de términos no asociados directamente a la enología o la vinificación pueden generar en el consumidor el deseo y la necesidad de consumir el vino. Es el caso de "historia", "tradición", "generaciones", “modernidad", "equilibrio", "legado", “innovación”, "ecosistema”, “disfrutar", "compartir”, "lienzo”, "experiencia”, "familia” o "entorno".

\section{Referencias bibliográficas}

Albisur, L. M. (2003). El mercado nacional del vino. En Castillo, J. S. (ed). El mercado del vino: reflexiones y propuestas de futuro. Universidad Castilla-La Mancha: Ediciones Universidad Castilla-La Mancha, I27-I42.

Bajo, F. (200I). El léxico científico-técnico del vino en el DRAE. En: Bargalló M. T. et. al., Las lenguas de especialidad y su didáctica. Actas del Simposio HispanoAustriaco. Tarragona: Universitat Rovira i Virgili, 69-80.

(2007). La terminología enológica del español en el siglo XIX. Tesis Doctoral. Tarragona: Universitat Rovira i Virgili.

Balbuena, M. C.; Álvarez, M. (2015). (ed.). Lenguajes especializados y traducción: vitivinicultura. Córdoba: Ediciones Don Folio.

Balbuena, M. C. (2015a). El tratamiento del término wîn/wein en la literatura alemana de la Edad Media. Alfinge. Revista de Filología 27, 29-4I.

(20l5b). Aproximaciones a la terminología vitivinícola en el par de lenguas alemán-español. En Balbuena, M. C. \& Álvarez, M. Lenguajes especializados y traducción: vitivinicultura. Córdoba: Ediciones Don Folio, 19-34.

Barahona, L. (2010). La traducción del spot publicitario del vino. En Ibáñez, M. (coord.), Vino, lengua y traducción. Valladolid: Secretariado de Publicaciones e Intercambio Editorial de la Universidad, 367-376.

Blouin, J.; Peynaud, É. (2004). Enología práctica. Conocimiento y elaboración del vino. Madrid: Mundi-Prensa.

Capanaga, P. (2004). Publicidad y nuevos consumos: algunos motivos para hablar del lenguaje del vino en la clase de E/LE. Actas XXII AISPI. Disponible en: 
https://docplayer.es/65748/0-Publicidad-y-nuevos-consumos-algunosmotivos-para-hablar-del-lenguaje-del-vino-en-la-clase-de-e-le-pilarcapanaga-universita-di-bologna.html.

Gómez, N. (2003). El mercado del vino y el rol del cooperativismo. En Castillo, J. S. (ed). El mercado del vino: reflexiones y propuestas de futuro. Universidad Castilla-La Mancha: Ediciones Universidad Castilla-La Mancha, 57-70.

Hidalgo, J. (20II). Tratado de enología. Madrid: Ediciones Mundi-Prensa.

Hidalgo, L. (2002). Tratado de viticultura general. Madrid: Ediciones Mundi-Prensa.

Ibáñez, M. (2002). La consolidación del vino de Rioja en el siglo XVII. Historia agraria. Revista de agricultura e historia rural 26, 33-68.

(2003). La documentación en traducción especializada: el caso de la vitivinicultura. En: Iñarrea, I. \& Salinero, M. J. (coords.), El texto como encrucijada: estudios franceses y francófonos. Vol. 2. Logroño: Servicio de Publicaciones de la Universidad de La Rioja, 537-552.

Ibánez, M. et. al. (2006). Vino, lengua y traducción. Valladolid: Secretariado de Publicaciones e Intercambio Editorial de la Universidad.

Muñoz, M. (2007). Análisis del mercado interior del vino en España. ACE. Revista de enología 88. Disponible en http://www.acenologia.com/ciencia88.htm. [Fecha de consulta: 20.09.2016].

Reynier, A. (2002). Manual de viticultura: guía técnica de viticultura. Madrid: MundiPrensa.

\section{Webgrafia}

Bodegas Barbadillo

Bodegas Campo Viejo. https://www.campoviejo.com/es/bodega.

Bodega Contador. http://www.bodegacontador.com/.

Bodegas Franco-Españolas. https://www.francoespanolas.com/.

Bodegas Habla. http://www.bodegashabla.com/.

Bodegas Lezaun. http://www.lezaun.com/.

Bodegas Luberri. http://www.luberri.com/es/.

Bodegas Marqués de Cáceres. https://www.marquesdecaceres.com/.

Bodegas Riojanas. http://bodegasriojanas.com/es/.

Bodegas Robles. https://www.bodegasrobles.com/.

Bodegas y viñedos Verum: https://www.bodegasverum.com.

Casa Rojo. https://www.mundovinum.com/260_casa-rojo.

Finca Las Caraballas. https://lascaraballas.es/.

Finca Moncloa. https://www.fincamoncloa.com/index.php.

Finca Santa Rosalía. https://www.fincasantarosalia.com/.

Grupo Yllera. https://www.grupoyllera.com/.

Premium Fincas. http://premiumfincas.com/. 